report acknowledges that "in the past amenity values appear to have been set aside too easily", and suggests that in future there should be a strong presumption against development which conflicts with park purposes.

Some of the parks' more obvious difficulties have arisen from the inherent conflict between preservation, on the one hand, and public enjoyment of the preserved facilities, on the other; the ever-increasing number of visitors has begun to threaten the very characteristics which attract the visitors in the first place. Road alterations have been carried out with no overall scheme in mind and in ways more appropriate to the urban than the rural environment; cars, coaches and caravans have been allowed to penetrate 'sensitive' areas; and roadside walls and verges have suffered from over-heavy vehicles.

The general problem here as Sandford sees it is that both park authorities and the government have been slow to react to changing circumstances; they have failed to come to terms with the fact that, although the walkers and climbers in the forefront of thinking during the 1940s are now more numerous than ever, the drivers have multiplied at an even higher rate. What, specifically, should be done? The Sandford recipe includes the routing of new trunk roads around the National Parks, the abandoment of any attempt to maintain uncongested traffic flow within the parks by means of new road development, refusal to permit alterations in existing road width or alignment, encouragement of peripheral parking linked to public transport inside the parks, and the resiting and screening of prominent caravan sites. Of course, it is one thing to identify sensible solutions, but quite another to carry them out-and the Sandford committee goes little into detailed implementation. On the other hand, there can be no doubt that the basic principle is sound and worth restating-that where the preservation and enhancement of beauty conflict acutely with the promotion of public enjoyment, the former must prevail.

Finally, the report suggests that there should be designated "national heritage areas" in which "the conservation of environmental qualities would be the supreme objective . . . . taking precedence over all others". There would be no settlement larger than a hamlet, no industrial development, no quarrying or mining, no reservoirs or defence works, no main roads or railways, no facilities for visitors, and visitor access would be limited to foot, bicycle and horse. This is the one genuinely radical suggestion in the whole report, although it is actually a minority proposal from four members of the committee. It deserves the widest debate, for this may be the last available opportunity for conserving "areas of the highest environmental quality".

\title{
correspondence
}

\section{Chilean symposium}

Sir,-We are scientists who firmly hold political opinions which differ from one to another. We are not concerned to try and understand these differences. We are, however, convinced that every scientist (like every nonscientist, indeed) has the right to hold what ideas he likes and to maintain them within his own country in the manner which he deems best.

We are similariy convinced that all political matters should be excluded from international scientific associations. Officialdom, no more than the organisers of, or the participants in international meetings, should neither impose nor allow any mixing of science and politics.

This is why we object to the following phrase "the re-establishment of social peace and internal order guarantees and secures to carry out this scientific event" in the invitation emanating from the Chilean section of the International Association of Volcanology and Chemistry of the Earth's Interior to attend a symposium in Santiago.

We cannot accept that a regime which has covered its large and unhappy country with blood, and which still continues to permit torture and political assassinations, should be permitted to include such a phrase in its circular of invitation to foreign scientists.
Needless to say, we do not propose to participate in this symposium and are of the opinion that a similar attitude should be adopted by any volcanologist sensible of the terrible Chilean tragedy, since his very presence there might tacitly imply tolerance from the human point of view.

\section{Yours faithfully, \\ Fr. BARBERI}

Pisa

\section{E. LOCARDI}

Rome

Pisa

G. Marinelli

Rome

M. Mittemperger

Catania

A. Rittmann

Paris

\section{H. TAZIEFF}

Paris

\section{J. VARET}

\section{Spilt milk}

SIR, - John Hall rightly adduces several arguments against the change from breast feeding to bottle feeding which is apparent in less developed countries. But his description of the character of the "Baby Killer", bottle feeding, is incomplete as it does not mention an effect of bottle feeding that will probably kill even more babies than the associated infections, malnutrition and poverty do. Lactation postpones postpartum ovulation and therefore contributes to birth spacing. It has been shown that prolonged lactation is indeed an important $\mathrm{factor}$ in controlling population growth. Populations in 1 es s developed countries that are changing from breast feeding to bottle feeding are likely to be insufficiently familiar with other means of family planning to compensate for this growth mechanism. I know of a case where all the female patients in a rural East African hospital were given a bra as a Christmas present, though family planning programmes in that area had not yet yielded any obvious result and the women concerned had hardly ever shown interest in bras. Whether due to well-intentioned grafting of our breastcentred culture into less developed cultures or due to deliberate promotion of dairy and bra industries, such behaviour is likely to add to baby killing population pressures. We should be aware of such incipient trends disturbing the balance between mortality and birth rates in less developed countries in addition to those already caused by Western medicine and technology.

Yours faithfully, J. WIND

Institute of Humaǹ Genetics,

Free University of Amsterdam. 